\title{
El bucanero reformado como creador de geografías: espacio y territorio en la costa peninsular yucateca*
}

\begin{abstract}
Ana Elvira Cervera Molina
Becaria posdoctoral en el Centro Peninsular en Humanidades y Ciencias Sociales - CEPHCIS (México) de la Universidad Nacional Autónoma de México - UNAM (México), asesorada por la doctora Carolina Depetris. Correo electrónico: aecm_21@hotmail.com. La autora es doctora en Humanidades, Especialidad Estudios de las Tradiciones por El Colegio de Michoacán (México). ORCID ID: https://orcid.org/00000002-8764-5033. Entre sus publicaciones recientes tenemos: "Breve reflexión sobre la etnia: Etnia e identidad en el Caribe" en Múltiples voces, diversos diálogos, Eds. Silvia Cristina Leirana Alcocer y Celia Esperanza Rosado Avilés (Mérida: UADY, 2017) y "Belice y Yucatán a través de las historias de viajes: dos siglos de escenarios traslapados. Diálogos a propósito del vacío" en Península Vol. XIV No. 2 (2019). Entre sus temas de interés se encuentran Fronteras, desplazamientos y migraciones en el Caribe continental.
\end{abstract}

Recibido: 2 de diciembre de 2018

Aprobado: 12 de marzo de 2019

Modificado: 30 de marzo de 2019

Artículo de investigación científica

DOI: http://dx.doi.org/10.15648/hc.37.2020.03

Una versión preliminar de este escrito se presentó en el Seminario Permanente "Estudios sobre el Caribe: perspectivas transdisciplinarias", en el marco de la investigación financiada por el Consejo Nacional de Ciencia y Tecnología - CONACYT (México): "Representaciones literarias de insularidad en Yucatán, Belice y Guyana. Hacia un modelo para el Caribe continental” (CB257673, 2016-2019). Esta publicación está bajo una licencia Creative Commons Reconocimiento-NoComercial 4.0 
El bucanero reformado como creador de geografías: espacio y territorio en la costa peninsular yucateca

\title{
Resumen
}

William Dampier fue un copioso proveedor de narraciones etnobotánicas que alimentaron la imaginación inglesa en Europa durante el siglo XVIII. Con un pasado obscuro como navegante mercenario, entre 1675 y 1678, Dampier visitó América Central con un especial foco en las bahías de Campeche y Honduras. A su paso, describió todo aquello de interés que a su juicio pudiera haber en el paisaje. Aunque minuciosa e ilustrada con mapas, su narración y los consecuentes dibujos que la acompañaron, estuvieron plagados de silencios relacionados con la población maya que habitaba la costa de la península de Yucatán.

Palabras claves: William Dampier, Campeche, viajes, piratas, espacio, Caribe.

The reformed buccaneer as a cartographer: space and territory along the coast of the Yucatan Peninsula

\begin{abstract}
William Dampier was an abundant provider of ethno-botanical narratives that fed the English imagination in Europe during 18th century. With a dark past as a mercenary sailor, between 1675 and 1678, Dampier visited Central America with special focus on the bays of Campeche and Honduras. In his trip, he described everything of interest that, in his opinion, could be in the landscape. Although meticulously detailed and illustrated with maps, his narrative and the consequent accompanying drawings were filled with silences related to the Mayan population, who inhabited the coast of the Yucatan Peninsula.
\end{abstract}

Keywords: William Dampier, Campeche, travels, pirates, space, Caribbean.

O bucaneiro reformado como criador de geografias: espaço e território na costa da península de Yucatán

\section{Resumo}

24 William Dampier foi um grande fornecedor de narrativas etnobotânicas que alimentaram a imaginação inglesa na Europa durante o século XVIII. Com um passado sombrio como navegador mercenário, entre 1675 e 1678, o Dampier visitou a 
América Central com especial ênfase nas baías de Campeche e Honduras. Na sua viagem, ele descreveu tudo aquilo de interesse que, em sua opinião, poderia estar na paisagem. Embora meticulosa e ilustrada com mapas, sua narrativa e os desenhos que o acompanharam, foram cheios de silêncios relacionados à população Maia que habitava a costa da península de Yucatán.

Palavras-chave: William Dampier, Campeche, viagens, piratas, espaço, Caribe.

\section{Le boucanier réformé en tant que créateur de géographies: espace et territoire sur la côte de la péninsule du Yucatan}

\section{Résumé}

William Dampier est l'auteur de riches récits ethnobotaniques qui alimentèrent l'imagination britannique en Europe pendant le 18ème siècle. Avec un obscur passé de corsaire, entre 1675 et 1678, Dampier a voyagé en Amérique Centrale et plus particulièrement dans les baies de Campeche et Honduras. Lors de ses voyages, il décrivit tout ce qui lui semblait digne d'intérêt dans le paysage. Bien que souvent minutieuse et accompagnée de cartes, sa narration ainsi que les dessins qui servent d'illustration n'ont pas eu d'échos relatif aux populations mayas qui vivaient sur la côte de la péninsule du Yucatan.

Mots clés: William Dampier, Campeche, voyages, pirates, l'espace, Caraïbe.

Por este tiempo, la guerra con los holandeses había concluido y con mi salud, recuperé mi antigua inclinación al mar.

\section{William Dampier ${ }^{1}$}

\section{INTRODUCCIÓN}

Pensar el espacio es pensar en quienes lo construyen día a día, por tanto, su existencia no es autónoma a la población que contiene, ni es ajena a los efectos del tiempo en la memoria de sus narradores. Es imposible concebir la imagen mental de una extensa superficie, terrestre o marítima, fuera de las experiencias narradas de quienes la recorrieron

1 William Dampier, Dos viajes a Campeche, con el facsímilar de la edición inglesa de 1705 (México: Miguel Ángel Porrúa Editores, 2004). 
previamente; sus imágenes, evocadas con nostalgia, son recordadas y persisten en los imaginarios colectivos a manera de catálogo finito de experiencias que traducen lo visto en algo concreto, aunque sus creadores se desvanezcan en la memoria. Los siglos XVI al XVIII fueron tiempos de "descubridores" y "aventureros", es decir, de seres que, ya sea por afanes científicos o por motivos claramente económicos, se lanzaron a la mar en busca de nuevos horizontes. Estos sujetos fueron creadores, muchas veces marginales, de historias de viaje y crónicas de encuentros, las cuales tradujeron el paisaje desconocido de los confines americanos en algo reconocible y susceptible de ser domesticado y explotado por Europa.

William Dampier² fue uno de estos hombres, tal vez, uno de los más importantes exploradores y aventureros ingleses, junto con James Cook, que circunnavegaron la superficie terrestre durante el período más álgido del expansionismo colonial inglés (siglo XVII-XVIII). Su pluma, pilar básico de su demandada literatura y fama, dio vida a una nutrida vorágine de imágenes que dotaron de consistencia física al paisaje mundial, sobre todo después del éxito inmediato de su primer libro $A$ New Voyage Round the World, publicado en 1697, con introducción de Sir Albert Gray y dedicado a Sir Charles Montagu, presidente de la Royal Society. En él, Dampier narraba su primera circunnavegación mundial al lado de marineros y bucaneros de la talla de Lion Wafer, William Ambrose Cowley y Bartholomew Sharp, entre otros, a quienes también podemos leer como narradores activos de su historia en otros relatos

2 El capitán William Dampier, mejor conocido en las colonias españolas como Guillermo Dampier, nació el 5 de septiembre de 1652 en East Coker, condado de Somerset, y murió en marzo de 1715 en Londres. Fue capitán, en la Royal Nary, de varias embarcaciones inglesas que partieron de la Gran Bretaña con el objetivo de explorar y cartografiar las costas de Nueva Holanda y Nueva Guinea. Dampier es ampliamente conocido por ser el descubridor de Australia y por elaborar extensos y detallados informes de lo que descubrió en esas tierras. En sus diversos viajes fue corsario y eventualmente bucanero, actividades que lo llevaron a recorrer tierras españolas en América Central visitando dos veces la bahía de Campeche, experiencia que es narrada en The Campeachy Voyages (1699), un texto apenas estudiado que ha perdido relevancia, al ser un apartado complementario, frente al estudio exhaustivo de la primera obra del autor. Dampier también es conocido por ser el primer hombre en haber circunnavegado el mundo entero tres veces. Diana y Michael Preston, A pirate of Exquisite Mind. Explorer, Naturalist, and Buccaneer: The Life of William Dampier, (New York: Walker \& Company. 2004), 2. 
como A New Voyage and Description of the Isthmus of America de Wafer, o el diario de viaje a las islas Galápagos de Cowley.

En el puente económico de carácter transoceánico que suponía el Atlántico durante el siglo XVII, la piratería representó una estrategia, bien elaborada y perfectamente organizada, ejercida por las naciones europeas que fueron excluidas del reparto papal que signó la bula Inter Caertera en el siglo $\mathrm{XV}^{3}$. Con el ejercicio del corso primero, y posteriormente el bucanerismo, Estados coloniales en marcado expansionismo, como Gran Bretaña y Francia, fracturaron hasta casi romper el complejo monopolio comercial de Indias y el sistema mercantilista que favorecía enormemente a la Corona española y a la de Portugal ${ }^{4}$. En este complicado y belicoso contexto surgió el primer texto de Dampier: A Nerw Voyage..., ${ }^{5}$ el cual tuvo una excelente acogida dentro del gusto literario europeo de su época, pues, para 1698, ya había sido reeditado tres veces por James Knapton, quien no dejó de solicitarle a Dampier más material para futuros volúmenes. De estas solicitudes se desprendieron: Voyages and Descriptions en 1699 que agrupaba: $A$ Supplement of the Voyage Round the World, The Campeachy Voyages y $A$ Discourse of Winds; $A$ Voyage to New Holland (Parte 1) en 1703, y $A$ Continuation of a Voyage to New Holland (Parte 2) en 1709. En los dos últimos se narra, en orden cronológico, su segunda circunnavegación mundial, hecha a bordo del St. George, y su tercer viaje, hecho a bordo del Duke. La primera obra de Dampier, A New Voyage..., contiene tres mapas ilustrativos: "A Map of the Middle Part of America" (Cap. 2),

3 Para profundizar en el tema de la piratería en América en general, y en Yucatán en particular consultar: Martha de Jármy Chapa, Un eslabón perdido en la historia. Piratería en el Caribe, siglos XVIXVII. (México: UNAM, 1983). Jorge Victoria Ojeda, "Piratería y estrategia defensiva en Yucatán durante el siglo XVIII". Revista Complutense de Historia de América, N. 20, (1994): 129-14. Y Alexander O. Exquemelin, Piratas en América (Sevilla: Editorial Renacimiento. 2013).

4 Manuel Lucena Salmoral, Piratas, corsarios, bucaneros y filibusteros (Madrid: Editorial Síntesis, 2005).

5 Los trabajos de Dampier, en especial el primero $A$ New Voyage Round the World, han sido ampliamente publicados y reeditado en Australia. Varios sitios web recuperan sus textos completos para su consulta, entre ellos: Proyect Gutemberg Australia (http://gutenberg.net.au/ebooks05/0500461h. html) basado en la primera publicación de 1927 de Argonauta Press, y The University of Adelaide Library (https://ebooks.adelaide.edu.au/d/dampier/william/new-voyage-round-the-world/complete.html\#introduction1.3) basada en la primera publicación de James Knapton de 1697 y con un amplio estudio introductorio de Norman Mosley Penzer. 
"A Map of the East Indies" (Cap. 10), y "Map of the Bashee Islands, Pulo Condore, etc." (Cap. 14) que se focalizan en ilustrar las bahías de Campeche y Honduras, las Indias Orientales, y Mindanao en el océano Pacífico, respectivamente.

En el presente trabajo se pretende comprender y analizar el cambio en la metodología de observación del entorno natural que Dampier aplicó al paisaje costero correspondiente a la península yucateca y a la bahía de Honduras. Para ello, se partirá del análisis discursivo de la obra del marinero inglés correspondiente a estos territorios con el objetivo de exponer que el hecho que Dampier cambiara el enfoque de la narración de una visión marítima a una humanista de corte cientificista, imbuida en el pensamiento propio del empirismo inglés de Bacon y Locke, modificó la consistencia del paisaje marcándolo como un escenario abierto para la colonización, favoreciendo con ello el asentamiento definitivo de los cortadores ingleses de palo de tinte en territorio español al ser configurado este como un territorio vacío.

Contrario a la imagen científica de Dampier como marino e hidrógrafo que ha perdurado ${ }^{6}$, él fue un bucanero reformado que encontró, por accidente, su vocación humanista y naturalista. Sus torpes inicios navegando los derroteros centroamericanos y dentro de los cortadores de palo de tinte, hacen del texto que le dedica a Campeche y Honduras una pieza clave para entender los modos de supervivencia, agrupación y asentamiento de la presencia inglesa en los territorios liminales de

6 La National Portrait Gallery en Londres guarda 4 retratos de Dampier. De ellos, el más famoso es el de Thomas Murray: un óleo sobre tela compuesto entre 1697 y 1698 que fue transferido del British Museum a la galería en 1879. En dicho retrato, Dampier aparece con cabello largo, una mirada serena que se dirige al observador, sosteniendo un libro en clara alusión a su labor intelectual, y escorzado sobre su lado izquierdo. En la ficha de identificación general Dampier aparece como "Circumnavigator and hydrographer". De los tres retratos restantes, los primeros dos corresponden a grabados hechos con base en el óleo de Murray: el primero de autor desconocido hecho a finales del siglo XVIII y principios del XIX, y el segundo hecho por Charles Sherwin, publicado en 1787. El cuarto retrato es el único que difiere sustancialmente de los anteriores en cuanto a composición, ya que este es un grabado elaborado por John Horsburgh, a principio del siglo XIX, en el que Dampier ya no aparece sosteniendo un libro. En él aparece escorzado sobre su lado derecho y con la levita abotonada hasta arriba. "William Dampier (1651-1715), Circumnavigator and hydrographer" (Londres, c. 1697), National Portrait Gallery (NPG),

https://www.npg.org.uk/collections/search/person/mp01176/william-dampier?search=sas\&sTex$\mathrm{t}=$ dampier (23 de noviembre de 2017). 
América Central, puesto que su carencia de pericia como cortador y marino, y las constantes solicitudes de su editor en Londres, le obligaron a un detallado ejercicio de observación y descripción. Fue esta situación la que dio como resultado un texto interesante, que funciona como una especie de catálogo narrativo de recursos costeros y de experiencias de superveniencia que, en palabras del propio autor, fue tan útil que pareciera como "sí hubiéramos sido enviados a propósito"

En sus descripciones de la zona, Dampier es quien activa la historia y los paisajes cambiando así la perspectiva de observación que prevalecía dentro del discurso científico, militar y comercial de la época (teoría de las ideas innatas), para alternarla con una visión literaria del paisaje. De este modo, a través de sus experiencias y de sus traspiés como bucanero en la costa yucateca, es él quien se vuelve el ojo informado que le permite conocer un mundo hasta entonces desconocido a todos aquellos que jamás han navegado allende ultramar, pero también, es la fuente confiable de información que ofrece un manual de supervivencia para futuros piratas forestales 8 .

En la lógica de la ecología cultural y del análisis textual y cartográfico, la retórica de control que ejerce el designio imperial colonial sobre los territorios susceptibles de ocupación aplica un mismo modelo de descripción tanto a lo social como a lo natural. En dicho modelo, aquello que no es útil para la explotación comercial o para la agricultura es considerado como desierto, y por tanto solo podrá ser caracterizado de una manera negativa, es decir, a partir de lo que no hay. En este sentido, hay una falsa creencia de que la visión imperial del narrador no afecta los paisajes sino solo a los sujetos y sus acciones, siendo que lo cierto es que el proceso de legitimación de la conquista conlleva, al mismo tiempo, una descripción del enemigo como salvaje y una presentación naturalizada del territorio concebido como hostil o insalubre?

7 William Dampier, Dos viajes a Campeche, con el facsímilar de la edición inglesa de 1705 (México: Miguel Ángel Porrúa Editores, 2004), 111.

8 Para profundizar sobre el desarrollo de la piratería forestal en la península de Yucatán consultar: Baños Ramírez, Othón. "Piratería forestal y economía-mundo: El caso de la Laguna (1558-1717)", Relaciones. Estudios de Historia y Sociedad, Vol. XXXIII, Nº 132 (2012): 75-107.

9 Pedro Tomé Martín, "La invención del desierto (y los salvajes chichimecas)”, en Dinámica y Trans- 
En este mismo tenor, nueve años antes de la publicación de Voyages and Descriptions, en 1690, se publicó An Essay Concerning Human Understanding de John Locke. En este texto, bajo una clara influencia del pensamiento de Francis Bacon, Locke, al igual que Dampier, apuntó la importancia de la experiencia y del uso de los sentidos como una forma de expandir el conocimiento científico. A esta corriente se le denominó empirismo inglés. Por su parte, Bacon, muerto en 1626, influenció enormemente todos los modos de navegación ingleses posteriores a su obra. En ellos, Bacon vio claros paralelismos entre la exploración geográfica y la expansión del conocimiento científico, posicionándose así como el pionero en un movimiento que revolucionaría la aproximación a la filosofía de la naturaleza ${ }^{10}$. En cuanto a la literatura de viajes, fue en su confrontación de la teoría de las ideas innatas dentro de An Essay... que Locke hizo un uso más extenso de los testimonios generados por viajeros y marinos, pues en estos se daba fe de la existencia de sociedades enteras donde los axiomas lógicos de conocimiento, que eran considerados innatos a la mente humana en occidente, no mantenían la misma lógica en cuanto a las reglas morales o la existencia de Dios. Con esta evidencia, Locke ataca la postura de "credulidad ciega" propia de la teoría de las ideas innatas para darle al hombre la "autoridad para ser el dictador de principios" 11 .

Con narraciones como la de Dampier y sus contemporáneos se observa un quiebre epistemológico clave en las formas de visualizar y concebir el conocimiento, en especial, en las formas en las que el paisaje es descrito y plasmado. En este quiebre ya el explorador no es fuente total de la verdad, ni su relato un documento verídico e incuestionable, como ocurría con las cartas de relación producidas durante el primer siglo de conquista en las Américas, sino que ahora todo lo descrito debía ser sistematizado con rigor científico, el cual debía basarse en una metodo-

formación de la Región Chichimeca, eds. Andrés Fábregas Puig et al. (México: Universidad Autónoma de Coahuila, Universidad Autónoma de Zacatecas, Universidad Estatal de California, Universidad de Guadalajara, El Colegio de San Luis, El Colegio de Jalisco, Universidad Autónoma de Nayarit y Universidad Autónoma de Aguascalientes, 2012), 50-52.

10 Diana y Michael Preston, $A$ pirate of Exquisite, 3.

11 Ann Talbot, The Great Ocean of Knowledge. The Influence of Travel Literature on The Work of John Locke (Leiden-Boston: Brill, 2010), 131. 
logía empírica susceptible de gozar de un principio de reproductividad inherente que a su vez permitiera el esclarecimiento y sistematización del saber geográfico, económico y político el cual era de gran interés al designio imperial inglés. En otras palabras, con el cambio de mirada del viajero, el paisaje narrado en las historias de viajes inglesas dejó de ser un calco de la realidad americana homologado ${ }^{12}$ con la realidad europea, para volverse una antinomi ${ }^{13}$ que resaltaba la diferencia americana con respecto a la europea en un juego de espías e intereses políticos. En este sentido, lo particular de la narración de Dampier sobre Campeche y Honduras no es su capacidad para narrar lo construido sobre el espacio, sino su pericia para exponer lo reconstruido de un espacio olvidado, mediante una serie meticulosa de recorridos que apuntan, cartografían, describen e inscriben materias primas, procesos y sujetos en los imaginarios europeos, todo ello a partir de una óptica de duda sobre la información proporcionada por el saber español a través de las cartas de relación y las descripciones geográficas elaboradas previamente. En esta nueva lógica de duda, propia del empirismo inglés, ninguna idea debería ser tomada como verdad sin antes haber pasado por un proceso de examinación y escrutinio que se observa en afirmaciones tales como: "He estado en tierra en estas atalayas, ya sea remando en canoa o caminando en tierra firme en toda esta costa, incluso cerca de la playa, pero nunca vi un pueblo cerca de la playa, ni siquiera casas junto a las cabañas de los pescadores de la costa, excepto solo en Sisal" ${ }^{\prime 14}$.

Según Rogelio C. Paredes el éxito editorial de Dampier se debe a factores propios que impulsaron la modernización de la sociedad inglesa con relación al resto de las naciones europeas. Dentro de estos factores, toma capital importancia la difusión de la imprenta y con ella la propagación de textos dentro de sectores sociales medios y bajos, lo cual incrementó el mercado del lector. De este modo, las obras relacionadas con viajes se convirtieron en un inventario de oportunidades de negocios que creció

12 La homonimia muchas veces se apoya en un parecido anecdótico en el que el recuerdo vago del narrador que asocia un elemento parcial se extrapola al todo creando con ello la homologación de seres o sucesos que de otra manera no tendrían parecido.

13 Contradicción entre dos principios racionales.

14 William Dampier, Dos viajes a Campeche, 111. 
rápidamente. ${ }^{15}$ Como se aprecia a lo largo de su obra, el extenso trabajo de exploración y descripción de Dampier y su posterior éxito de publicación no fueron ajenos a las tendencias de consumo editorial propias de finales del siglo XVII y durante todo el siglo XVIII. La insaciable demanda de sus publicaciones, aunado a la puntal metáfora descriptiva de su pluma, hicieron de sus textos y de su editor James Knapton una pieza indispensable para el comercio literario transatlántico, en especial, la segunda parte de Voyages and descriptions: "Two Voyages to Campeachy, with a Description of the Coasts, Product, Inhabitants, Logwood-Cutting, Trade, \&c. of Jucatan, Campeachy, New-Spain, \&c." ${ }^{16}$ en donde se narran los procesos de corte, extracción y exportación de palo de tinte ${ }^{17}$ por parte de taladores ingleses en territorio español. Esta actividad representaba una veta económica vinculada con la empresa de colorantes textiles que durante mucho tiempo fue explotada satisfactoriamente por Gran Bretaña en detrimento de la monarquía española, lo cual ocasionaría un intenso conflicto diplomático y administrativo entre las coronas ibérica y británica, que se vio abiertamente citado en diferentes tratados internacionales como el Tratado Godolphin de 1670 o la Paz de Utrecht de 1713. En esta lógica, Dampier es enfático con el

15 Rogelio C. Paredes, "Los viajes de William Dampier (1678-1701) y su recepción europea a través de los libros del Museo Etnográfico de Buenos Aires”, Espacios de Crítica y Producción, № 40 (mayo, 2009): 129.

16 La edición totalmente en español de las obras completas de Dampier aún es un asunto pendiente en la historiografía marítima de México. Sin embargo, reconociendo esta carencia, en 2004 el Gobierno del Estado de Campeche publicó Dos viajes a Campeche con el facsímil de la edición inglesa de 1705, en edición bilingüe hecha por el Grupo Editorial Miguel Ángel Porrúa con introducción de José Manuel Vilalpando César y traducción de Ana García Bergua. En el presente trabajo, todas las citas referentes a The Campeachy Voyages fueron tomadas de esta edición.

17 El punto central de la diferencia entre palo de tinte, palo de Campeche y brasilete estriba no en su clasificación como especies botánicas, ya que todos estos nombres refieren la misma especie (con excepción del brasilete que se denomina Heamatoxylum Brasiletto), sino en un asunto de percepción de la calidad de la madera y el colorante. Tanto el palo de Campeche como el palo de tinte son nombres que recibe la misma especie, el Haematoxylum Campechianum, la cual es endémica de la península de Yucatán. Su valor es principalmente como tintórea, aunque también se usó para reforzar barcos y construir armas por su gran durabilidad. El palo que era extraído de la costa campechana (palo de Campeche), en la Laguna de Términos o Isla de Tris, hoy Isla del Carmen, se percibía de mayor calidad y era mucho más apreciado que los demás. El palo de tinte, por tanto, era una denominación genérica usada para referir el tipo de madera y a la tintórea, mientras que el brasilete era un término que también se usaba indistintamente para referir la caoba u otras maderas extraídas, principalmente, de la Isla de Cozumel o Cabo Catoche. La confusión con estos términos deriva del uso indiscriminado que hicieron los españoles peninsulares en su denominación, así, los términos adquirieron o perdieron su valor distintivo inicial, en cuanto a percepción de la calidad, y para el siglo XVIII su uso era indistinto. 
lector al apuntar que vio "grandes oportunidades de hacer dinero ahí, si tan solo los hombres fueran diligentes y frugales" $"$.

Después de una revisión detallada de la narración, el lector sabe que el texto de Dampier le habla directamente a él, pero también que es escrito a posteridad, pues en él se incluyen reflexiones y observaciones personales hechas por el autor, o por algún capitán contemporáneo, varios años después de que la travesía narrada tuviera lugar. Esta postura se afirma en sentencias tales como "Nunca estuve en tierra ahí, pero conocí a algunos muy familiarizados" 19 . Para la elaboración de su relato, Dampier recurrió a sus observaciones, a la memoria, a la información obtenida por escrito, así como a la recabada "de oídas" a través de terceras personas para dar validez a los datos proporcionados. Un ejemplo de esto se observa en las dos cartas que se transcriben y anexan al texto sobre la vaca de montaña y su relación con el hipopótamo africano. La primera proviene de un hombre ilustrado de Holanda cuyo nombre no se menciona, pero que se refiere estar ubicado en Leiden y que fue contactado por el Capitán Covent de Portbury desde Bristol. ${ }^{20}$ La segunda proviene del Capitán Rogers y está fechada en 1695, es decir, 18 o 19 años después de haber tenido lugar su segundo viaje a Campeche ${ }^{21}$.

De lo anterior se desprende el carácter que como narrador adquiere Dampier sobre la marcha, pues más que marino y eventual bucanero, él se convirtió en un intelectual humanista en busca de expediciones científicas que impactó la imaginación de personajes de la talla de Jonathan Swift y Daniel Dafoe ${ }^{22}$. Aunque no estuvo exento de realizar actividades piráticas, sus habilidades en el "arte de marear" y en la observación y descripción etnobotánica fueron superiores a sus correrías como corsario, convirtiéndolo así en un bucanero reformado. Como tal, al igual que muchos hombres de su tiempo, él tenía la habilidad de escribir, de narrar con expertise literaria lo que presenció, experimentó y sintió, abriendo con ello un nuevo mundo, narrado en primera persona, de algo que hasta ese momento solo había sido presenciado por otros y que había llegado hasta el mercado editorial inglés como traducciones

18 William Dampier, Dos viajes a Campeche, 71.

19 William Dampier, Dos viajes a Campeche, 55.

20 William Dampier, Dos viajes a Campeche, 239.

21 William Dampier, Dos viajes a Campeche, 245.

22 Diana y Michael Preston, A Pirate of Exquisite, 3. 
de obras extranjeras. En este sentido, la pluma de Dampier no solo narró y describió lo registrado por sus ojos, también almacenó lo referido por fuentes secundarias, unas veces confiables, otras de dudosa procedencia, y lo contrastó con el conocimiento científico accesible en su tiempo, dando pie a una metodología científica que sentaría precedente en la escena mundial.

Como es evidente, Dampier escribe en retrospectiva, activado por la memoria. Esto convierte a sus escritos difíciles de fijar cronológicamente, pues él como autor accede a sus recuerdos espontáneamente traduciendo las imágenes que ha observado para luego contrastarlas con el catálogo finito de experiencias europeas compartidas, de las cuales habían abrevado las historias de viaje escritas con anterioridad. Por tanto, no es de extrañar que su narración este salpicada de referencias a capitanes ingleses, ataques piratas y descripciones geográficas con tintes comerciales propias de su tiempo, ya que al final, es un pirata literato, un bucanero reformado, quien relata y que se encuentra alineado con el designio imperial británico de su época. En este sentido, es posible afirmar que el topos literario del viajero "enfatiza la homogeneidad cultural del grupo al que pertenecen los héroes cuyas hazañas se narran, frente a una difusa heterogeneidad de los que habitan el terreno desierto". ${ }^{23}$

\section{UN VIAJERO INGLÉS EN LAS COSTAS CENTROAMERICANAS}

Para las costas yucateca y hondureña, tanto a nivel de transmisión textual como de contenido, $A$ New Voyage Round de World, Voyages and Descriptions y " $A$ Map of the Middle Part of America" resultan por demás piezas reveladoras. Los capítulos 1 y 2 del primero y las tres partes en que se divide el segundo ("A Supplement of the Voyage round the World", "Two Voyages to Campeachy", y "A Discourse of Trade-Winds") no solo son invaluables piezas etnográficas y un verdadero manual de explotación que se complementan una al otro, sino que dan fe del método de observación científica aplicado por Dampier. En estos textos se describe el período durante el cual nuestro bucanero reformado tuvo la oportunidad de navegar territorio español, francés y holandés, describiendo su contenido, el cual es ilustrado con el mapa que lo acompaña ("A Map of the Middle Part of America"). El mapa

23 Pedro Tomé Martín, "La invención del desierto”, 57. 
(Fig. 1) está focalizado en la península de Yucatán, en especial en la bahía campechana y en la hondureña, zonas de gran interés para el autor, en cuanto a que constituían vetas importantes de palo de tinte. A nivel poblacional, la primera bahía está conformada por mayas (sumisos o insumisos) y por españoles peninsulares y criollos. La segunda, está conformada por indios mískitos que se extienden a lo largo de Honduras y Nicaragua a los cuales Dampier describe de la siguiente manera:

"The Moskitos are in general very civil and kind to the English, of whom they receive a great deal of respect, both when they are aboard their ships, and also ashore, either in Jamaica, or elsewhere, whither they often come with the seamen. We always humour them, letting them go any whither as they will, and return to their country in any vessel bound that way, if they please" 24 .

\section{Figura 1}

"A Map of the Middle Part of America"

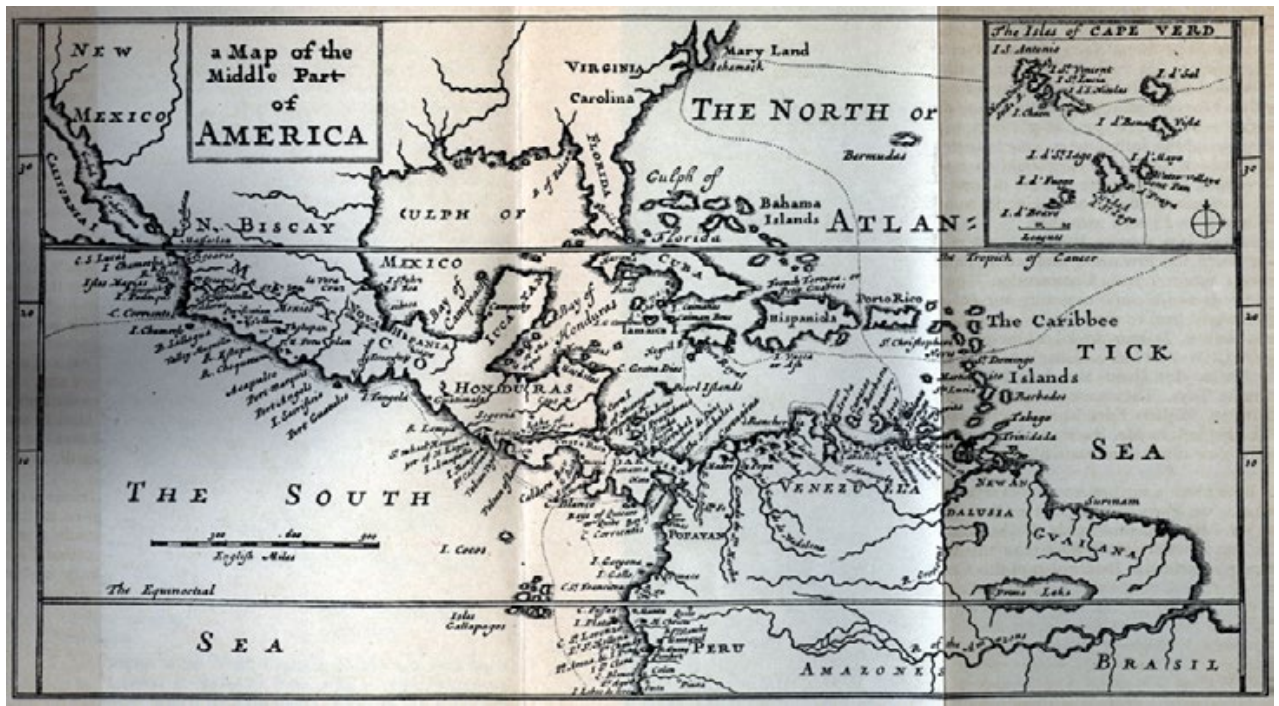

Fuente: William Dampier, "A Map of the Middle Part of America”, A New Voyage Round the World. (London: Knapton, 1697), http://gutenberg.net.au/ebooks05/0500461h.html\#0500461h-06 (20 de mayo de 2016).

24 William Dampier, A New Voyage Round the World. Chapter 1. An account of the Author's return out of the South Seas, to his landing near Cape St. Lawrence, in the Isthmus of Darien: with occasional description of the moskito Indians, (1681), https://ebooks.adelaide.edu.au/d/dampier/ william/new-voyage-round-the-world/complete.html\#chapter1 (20 de mayo de 2016). 
"A Map of the Middle America", más que una aproximación topográfica al territorio correspondiente a la América tropical septentrional, es una declaración de intereses que se enmascaran en sucesivos silencios, los cuales se expresan en el dibujo a través de espacios en blanco y vacíos dejados en zonas estratégicas ${ }^{25}$. Con una fuerte influencia de los mapas portulanos, el dibujo de Dampier ilustra el derrotero que describe su narración al tiempo que compara dos bloques costeros continentales (la bahía de Honduras y la bahía de Campeche), en cuanto a la relación que los ingleses pueden establecer con la población indígena local. Por un lado, la península de Yucatán ("Iucatan") aparece deformada, es decir, aparece como un bloque de tierra alargado que se conecta con el resto del territorio continental mexicano por un brazo que es casi del mismo tamaño que la punta; en su interior, no aparece referencia alguna a ciudades españolas grandes, como Valladolid o Mérida, a pesar de que estas ya habían sido fundadas al menos un siglo antes de su viaje y que son mencionadas en The Campeachy Voyages. Lo que sí aparece es la clara referencia a la ciudad de Campeche ("Campechy"). Por su parte, en la bahía de Honduras no encontramos referencia a ninguna urbe propiamente establecida, ni siquiera en sus inmediaciones costeras, pero sí hallamos una referencia directa a los indios mískitos ("Moskitos") en clara proximidad con Jamaica ("Iamaica"), idea que se refuerza en el texto que acompaña el mapa en el cual se lee: "They have no form of government among them, but acknowledge the King of England for their sovereign. They learn our language, and take the governor of Jamaica to be one of the greatest princes in the world"26. La amistad y fraternal relación que aparentemente mantuvieron los indios mískitos de la bahía de Honduras con los ingleses, en especial después de que Jamaica se volviera territorio británico en 1655, fue un malestar constante para la corona española que presumía tener dominio de toda el área continental ${ }^{27}$.

25 Para ahondar más en el tema de los silencios y los vacíos cartográficos consultar John Brian Harley, La nueva naturaleza de los mapas. Ensayos sobre la historia de la cartografía (México: Fondo de Cultura Económica, 2005).

26 William Dampier, $A$ New Voyage, Chap. 1, 1681.

27 Gerhard Sandner, Centroamérica \& el Caribe Occidental (Colombia: Universidad Nacional de Colombia, Sede San Andrés, 2003). 
De lo dibujado en el mapa por Dampier llaman la atención los espacios dejados en blanco, pues mientras que en el área dedicada a la península de Yucatán no encontramos referencias de la población maya local (la cual desaparece para darle espacio a los asentamientos españoles claramente configurados y ordenados, mismos que son expresamente evitados o rosados tangencialmente por los ingleses), en la costa hondureña la población indígena autóctona aparece de la mano de la concepción ilustrada del buen salvaje, en la que autoridades inglesas y mískitas se reconocen mutuamente siempre y cuando los segundos acepten y abracen voluntariamente el yugo de los primeros en un acto pacífico y armónico. Es así que a través de su sumisión los indígenas mískitos se visibilizan en el mapa, a través de una huella toponímica que rompe el espacio en blanco y los rescata abruptamente del silencio, llevando hacia ella la mirada del lector. Los silencios dejados por Dampier en este caso son muy declarativos, pues como es bien sabido el primer paso para ocupar el espacio es proceder a su vaciamiento simbólico. En otras palabras, hay que producir el vacío, para a partir de allí empezar el llenado civilizatorio que conllevará la total apropiación.

Para ahondar más en este juego de silencios entre los diferentes tipos de población indígena local existente en la zona durante el siglo XVII, The Campeachy Voyages resulta crucial. En este texto, Dampier entra de lleno a explorar la península de Yucatán y se vuelca a describir puntualmente la labor de los cortadores de palo de tinte, centrándose en lo que él llama "Jucatan, Campeachy, New-Spain", pero que en realidad corresponde geográficamente a lo que actualmente es desde Veracruz al oriente, la península de Yucatán y Belice, siguiendo, probablemente, la ruta trazada por Juan de Grijalva en 1518. No es descabellado suponer que Dampier tenga conocimientos geográficos previos del área yucateca y hondureña aun antes de siquiera recorrerla, pues para el momento de sus viajes ya ha convivido estrechamente con otros marineros, a través de sus múltiples embarques. La transmisión de este conocimiento pudo darse desde Londres, en la Royal Navy, o en Jamaica, antes de embarcarse rumbo a la sonda campechana y la bahía de Honduras. Sin embargo, lo interesante de su narración parte de su capacidad de observación y contraste. En su texto, Dampier ofrece una detallada etnografía del estilo de vida y las costumbres de los ingleses que explotaban 
territorio y recursos españoles dentro y fuera de los límites acordados por las metrópolis coloniales en el Tratado de Godolphin, en el cual se le daba una tibia legitimación política por parte de España a la presencia inglesa en tierra firme a través de una serie de concesiones forestales otorgadas para la explotación del palo de tinte.

De los dos viajes que Dampier realizó a Campeche, el primero duró 13 semanas, iniciando a principios de agosto de 1675 al partir de Jamaica rumbo a la Isla de Tris en compañía del Capitán Wren y el Capitán Johnson, comandante de un queche perteneciente a Nueva Inglaterra. Este viaje se describe en el capítulo I, el cual está dividido en dos bloques: uno previo sobre su llegada a Jamaica para trabajar en la administración de la plantación del Coronel Hellier de East-Cocker, y uno, posterior, sobre su embarco con los ya mencionados Capitán Wren y Johnson. La ruta de este primer viaje abarca Pequeños Caimanes, Cayo Manbrack, Isla Pinos, Cabo Corrientes y Cabo Antonio, al sur de Cuba, hasta llegar a Cabo Catoche, en donde se señala que la costa continua hacia el sur unas 40 leguas hasta Isla Cozumel, desde donde se dobla al suroeste para dirigirse hacia la bahía de Honduras. En frente de Cabo Catoche se refiere a una pequeña isla llamada Loggerhead; la cual podría inferirse que se trata de Holbox ${ }^{28}$. De Cabo Catoche la derrota de Dampier continua sobre el Monte, Río Lagartos, Sisal y Cabo Condecedo, el cual unas veces se sitúa cerca de Río Lagartos ${ }^{29}$, otras cerca de Sisal ${ }^{30}$. De ahí el viaje continúa hacia la Isla de Tris, la cual se refiere como el camino útil solo para los barcos grandes, para los barcos pequeños se recomienda navegar 3 leguas más lejos hacia Cayo Un Arbusto. Al ser el barco del Capitán Johnson un queche, el navío se vio obligado a anclar en el ya mencionado Cayo Un Arbusto, en donde alrededor de 250 hombres, en su mayoría ingleses, estaban dispuestos a cambiar su palo de tinte por ron y azúcar. ${ }^{31}$ En el tornaviaje de Isla Tris a Jamaica, la ruta se vuelve accidentada gracias a un norte que los obliga a encallar en el Arrecife de los Alacranes. De regreso a Port Royal la tripulación pasa

28 Adrián Curiel Rivera, "Viajes del Pirata Dampier a Campeche", en, eds. Carolina Depetris, (Mérida: UNAM, 2015), 10.

29 William Dampier, Dos viajes a Campeche, 57.

30 William Dampier, Dos viajes a Campeche, 67.

31 William Dampier, Dos viajes a Campeche, 69. 
por Gran Caimán, luego se ve obligada a pasar una temporada en Isla Pinos, cerca de una guarnición española, hasta finalmente pasar entre Bluefields Point y Point Nigrill, lo cual favoreció su retorno hasta Port Royal en Jamaica.

Para los fines del estudio de los paisajes y sus habitantes llama la atención la descripción que Dampier hace de Cabo Catoche en donde dice:
“es tierra baja cerca del mar, pero algo más alta mientras más se aleja uno de la costa. Todo él está tupido de árboles de diversas suertes, especialmente palo de tinte, por lo tanto antiguamente lo frecuenta- ban mucho más los hombres de Jamaica, quienes venían hasta aquí en balandras para cargarlas de ellos, hasta que todos los árboles de palo de tinte cerca del mar fueron cortados; ahora está abandonado por completo, ya que acarrearlos hasta la orilla exige más trabajo que talar, cortar y astillar. Además, encuentran mejor madera en estos días en las bahías de Campeche y Honduras, y tienen que hacer poco camino para cargarlas; no más de 300 pasos, cuando yo estuve ahí, mientras que en Cabo Catoche se veían obligados a cargarla 1,500 pasos antes de partir del lugar"32.

A diferencia de la actitud amistosa que se describe en $A$ New Voyage... con respecto a la población indígena mískita de la bahía de Honduras, en The Campeachy Voyages la población indígena maya en la península de Yucatán se muestra temerosa y mira con recelo la presencia de corsarios y cortadores de palo de tinte en la zona, adoptando una actitud que raya en lo fantasmagórica: de la misma manera que no aparecen en el mapa que Dampier ofrece al lector europeo en su famoso primer libro, ellos desaparecen del paisaje, usando el monte, la selva o el mar como herramientas de camuflaje.

"Desde que los corsarios y los barcos de palo de tinte navegan por esta ruta, estos pescadores son muy silenciosos, pues a menudo han sido atacados por ellos. Así que ahora, cuando se encuentran en el mar, si ven una embarcación en seguida hunden sus canoas hasta el borde del

32 William Dampier, Dos viajes a Campeche, 53. 
agua, ya que las canoas, cuando se encuentran llenas de agua, no se hundirán más, y ellos mismos se acuestan con sus cabezas justo encima del agua, hasta que el barco que vieron ha pasado o está cerca. Los he visto desde el barco y entonces han desaparecido de repente"33.

Este recelo generalizado de la población maya local hacia la presencia inglesa probablemente se deba a dos causas. La primera al uso frecuente del secuestro y la esclavización de la población indígena, con fines de obtener mano de obra para la extracción del palo de tinte, que practicaban comúnmente los taladores. La segunda, al hecho que los indios mayas que se encontraba Dampier en su camino eran probablemente indios libres que no deseaban ser incorporados al sistema de encomiendas. Pero, cualquiera fuera la causa de su precautorio camuflaje, en todos los casos descritos desaparecer parece significar para los indígenas mayas una elaborada estrategia de supervivencia, que solo le era posible a aquellos que vivían en los márgenes del imperio, allí, en las zonas liminales donde ni Dios mandaba, es decir, en el paisaje deshilachado de la imaginación de Dampier. En el texto, los indígenas mayas secuestrados son referidos como "marineros indios" y son considerados objetos de compra-venta al igual que las embarcaciones que se les aseguraban en el proceso de secuestro. En esta relación, el indígena pierde su especificidad como parte importante de un grupo cultural para, de esta forma, volverse un indio pacificado que se homogeniza con el sistema y ya no un rebelde acimarronado.

Según Curiel Rivera, tanto en el primer como en el segundo viaje de Dampier, la geografía se va configurando como un cambiante escenario móvil en donde el autor coloca cuidadosamente, una a una, toda las piezas animales y vegetales de una naturaleza desconocida que es objeto de constantes comparaciones con otras especies existentes o conocidas en Europa $^{34}$. Sin embargo, en contraste con el meticuloso detalle ejercido sobre la fauna y flora endémica de la zona, las observaciones hechas sobre la población maya local son mínimas. Como piezas, los indios mayas aparecen clasificados en dos grupos: sumisos e insumisos. Los

33 William Dampier, Dos viajes a Campeche, 57.

34 Adrián Curiel Rivera, "Viajes del Pirata Dampier", 11. 
insumisos tienen una gran vocación al mar y un conocimiento profundo de la selva y sus productos, lo cual los hace escurridizos, mientras que los sumisos viven totalmente doblegados cerca de los principales centros urbanos españoles que se encuentran tierra adentro, los cuales los mantiene lejos de la acción pirática en las costas. En palabras del propio Dampier, ellos "No se plantan cerca del mar, como se hace en las costas de Caracas, sino por lo menos 8 o 10 millas arriba en el campo"35.

Si bien la descripción del primer viaje de nuestro bucanero reformado es de corte panorámico, tanto con la población como con el paisaje, el segundo tiene un foco claro: el palo de tinte. Este viaje duró más de un año y es relatado en los capítulos II al VI, en donde se describe mucho más a detalle las actividades de los cortadores en la sonda campechana y también se ofrecen más detalles de los indios sumisos ${ }^{36}$, de los cuales se dice:

"Los indios, cuyo negocio, he dicho, consiste en recoger la sal en montañas, esperan aquí por turnos durante toda la temporada de desbordamiento, no menos de 40 o 50 familias cada vez. Aún así no hay casas para que duerman, ni les importa, porque cada semana los releva una provisión fresca de indios y todos duermen al aire libre, algunos en el suelo, pero la mayoría en hamacas muy pobres atadas a los árboles o a postes clavados en el suelo para ese propósito. Su suelo no es mejor que su alojamiento, ya que no tienen mejor alimento cuando se encuentran aquí que tortillas y pozol [...] Al terminar la temporada de desbordamiento de la sal, los indios vuelven a casa a sus hogares fijos y ya no se ocupan de la sal" 37 .

35 William Dampier, Dos viajes a Campeche, 257.

36 Las fechas de inicio y término de sus viajes, así como la numeración de los capítulos no es precisa. $\mathrm{El}$ autor es tremendamente vago en estos detalles, sus cuentas sobre los tiempos transcurridos no coinciden con los tiempos de viaje señalados. La numeración de sus capítulos se repite, pues existen dos capítulos II, o salta de uno a otro, va del segundo capítulo II al IV y de ahí salta al VI, pero eso no menoscaba lo preciso de su narración etnobotánica ni lo puntual de sus relatos sociológicos, solo dejan claro que este es un texto escrito en retrospectiva con una finalidad científica y etnográfica, no un texto historiográfico con afanes cronológicos.

37 William Dampier, Dos viajes a Campeche, 118. 
Por su parte, es en este segundo viaje en el que el paisaje adquiere un protagonismo mayor, una vez que se ha dejado claro la tipología de los cortadores diciendo que: "Es muy cierto que los taladores de palo de tinte que se encontraban en la bahía cuando yo estaba ahí eran todos enviados o desarraigados" 38 . Sin embargo,

"son por lo general hombres fuertes y robustos, y cargarán pesos de 300 a 400 pesas, pero se deja a la elección de cada hombre cargar lo que le place, y por lo común se ponen de acuerdo muy bien al respecto, porque se conforman con trabajar muy duro" 39 .

\section{El paisaje roto en YuCATÁn: El ESCEnARio PERFECTO PARA DESAPARECER}

The Campeachy Voyages es una narración rica en descripciones del paisaje peninsular yucateco. En ellas el escenario dispuesto es casi siempre descrito como difícil, roto, deshilachado, poco fértil o deshabitado. $\mathrm{O}$ bien, bajo la consigna que si en algún tiempo estuvo habitado ahora se encuentra en el abandono por parte de España, pero en uso corriente por ingleses interesados en el comercio de palo de tinte.
"Entre El Monte y Cabo Condecedo, cerca del mar, hay multitud de pequeñas manchas de manglares, que a la distancia parecen como islas; pero al acercarse, cuando aparecen otros árboles más bajos, semejan un terreno roto y deshilachado, y al final la tierra se presenta muy llana a la vista" $"$.

La cita anterior hace referencia muy probablemente a las ciénegas pringadas de petenes ${ }^{41}$ que son características de la península de Yucatán. Dichas ciénegas son áreas pantanosas especialmente extensas entre la Ciudad de Campeche y Sisal. En la narración, Dampier hace clara alu-

38 William Dampier, Dos viajes a Campeche, 193.

39 William Dampier, Dos viajes a Campeche, 193.

40 William Dampier, Dos viajes a Campeche, 55.

41 En el área peninsular yucateca se denominan 'petenes' a las islas de vegetación arbórea que se encuentran inmersas en marismas. Dichas marismas se hallan en territorios bajos y pantanosos que se encuentran próximos a la costa. Fernando Tun Dzul, Jorge Carlos Trejo Torres y Rafael Durán García, "Petenes", CICY, 1, (1996). 
sión a que estos particulares escenarios se hallan en completo abandono al momento de su visita. De este modo, el paisaje es descrito como un terreno roto y deshilachado que no parece guardar ningún tipo de orden ni armonía interior, aunque de lejos lo parezca, al no conformar un bloque de tierra continuo como se espera del escenario costero, sino un sinfín de fragmentos de pantanos caprichosos que se disponen como antesala del bloque costero real. Con imágenes como estas Dampier inaugura lo literario del paisaje. Así, el paisaje roto se vuelve metáfora de lo inasible y lo desordenado al establecer un juego de perspectivas, en donde el escenario muta ante los ojos del navegante, lo engaña y se transforma al impactarle la distancia. En The Campeachy Voyages, Dampier describe a la costa yucateca como un espacio vacío ${ }^{42}$ en el que, aunque lo hubo en algún tiempo, se carece de toda presencia humana civilizada y de todo orden interior, puesto que el paisaje salvaje adolece de una no domesticación por parte de la mano del hombre civilizado, pues en él no hay infraestructura de gobierno, traza urbana o presencia

42 El espacio como sinónimo de vacío es la noción más generalizada que existe del mismo en la vida cotidiana, aunque problemática y errónea hoy día, esta visión permite entender la lógica de concepción, producción y ocupación del territorio que permeaba el pensamiento colonial a lo largo de los siglos XVI al XIX. A la hora de historiar la concepción del espacio, es decir, al momento de ponerlo en un plano sincrónico es interesante ir a los orígenes de esta noción, los cuales Hiernaux y Lindón ubican, en una segunda instancia, en los enfoques filosóficos idealistas de la noción de espacio continente, en los que, según Leibnitz, "El espacio es un orden mental en el cual los cuerpos coexisten, y en consecuencia, cabe aquí la posibilidad de vacío, es decir, que el espacio viene a constituirse en un sistema de relaciones, que existe independientemente de los individuos". Daniel Hiernaux y Alicia Lindón, "El concepto de espacio y el análisis regional", Revista Secuencia Nº. 25, (enero-abril, 1993), 93.

En esta lógica, también resulta productivo hacer una historización del vacío en la que podemos rastrearlo como una ausencia, es decir, como un espacio donde no exista un orden mental en donde los cuerpos puedan coexistir. Con respecto a esto Macías Zapata dice que "el vacío se fundaba para resaltar la ausencia del aparato administrativo y de control correspondiente al poder hegemónico del Estado colonial o del nacional, paralelo a la total o insuficiente ocupación del lugar”. Gabriel Macías Zapata, El vacío imaginario. Geopolítica de la ocupación territorial en el Caribe oriental mexicano (México: CIESAS, 2004), 11; Antonino Vidal Ortega y Raúl Román Romero, “De vasallos británicos a súbditos españoles. Los márgenes borrosos del imperio en el caribe occidental a finales del siglo XVIII y principios del siglo XIX", Temas americanistas, N. 40 (junio, 2018): 161-187.

Así, el espacio vacío, para la época colonial, es un espacio carente de orden mental al adolecer de la ausencia de un aparato administrativo y de control que lo regule y ordene, por tanto, en este momento histórico hablar de vacío no es hablar del espacio, sino es hablar de ausencia, de carencia de orden y acción, es decir, de algo inculto o deshabitado que "necesita" ser habitado, domesticado y ordenado por un poder hegemónico. 
humana reconocible, sin embargo, es bien sabido que los nativos están ahí, pero se ocultan a la mirada extranjera:
"No es cosa nueva que en estas partes boscosas de América huyan pueblos enteros de indios de una sentada y se establezcan en selvas no frecuentadas para disfrutar de su libertad; si por accidente son descu- biertos, se mudarán de nuevo, lo cual harán fácilmente pues sus enseres domésticos son muy pocos, además de sus hamacas y calabazas" ${ }^{43}$.

En la narración de sus peripecias, nuestro bucanero reformado evidencia la doble agenda de los taladores ingleses durante el siglo XVII: por un lado, eran leñadores y empresarios, pero por otro, ejercían actos piráticos indistintamente contra aquellos que se encontraban a su paso. Esta actividad pirática marcó fuertemente el devenir de estos territorios, tanto de la península de Yucatán como de Honduras, principalmente durante el siglo XVIII, en donde, extracción de palo de tinte y piratería irían de la mano; hasta que en 1774 se declarara el palo de tinte libre de derechos y se inaugurara una nueva época diplomática que dejaría atrás la etapa heroica de encuentros violentos entre corsarios y autoridades reales.

Más adelante en su narración, Dampier describe brevemente la península de Yucatán haciendo hincapié en los centros de poder, en cómo está integrada la población que la habita, cuáles son sus prácticas de supervivencia y cómo interactúa dicha población con los corsarios ${ }^{44}$ que comúnmente mantienen asolada la costa. A partir de esta descripción se puede inferir que existen dos tipos de indios mayas: los dominados y los no dominados; y que existente dos tipos de territorios: los interiores, ya configurados en urbes habitadas por españoles e indios dominados, y los costeros, descritos como semidesolados, salvajes y de libre tránsito:

"No lejos de ahí hay un fuerte con 40 o 50 soldados para resguardar la costa y de este lugar sale un camino a través del campo que lleva a la ciudad de Mérida. Es esta la principal cuidad en toda la provincia de

43 William Dampier, Dos viajes a Campeche, 221-223.

44 En el texto original en inglés, Dampier se refiere a los piratas como "Privateers". 
Yucatán y se encuentra habitada en su mayor parte por españoles. Aun así hay muchos indios entre ellos, que viven dominados, como el resto de los indios de este país. La provincia de Yucatán, especialmente esta parte norte y sobre todo la parte más oriental de ella, es poco fértil en comparación con aquel suelo rico más hacia el oeste [...] Por lo tanto, cuando los piratas vienen a esta costa, no temen desembarcar y rondar, como si anduviesen por su propio país" 45 .

Es en la zona costera donde Dampier insiste en lo agreste y salvaje del paisaje, en donde incluso la obtención de comida a través de la caza puede ser una actividad peligrosa. Sin embargo, con mucha naturalidad, el autor agrega que, dado el poco poblamiento de las costas o al ser los asentamientos poblacionales principalmente indígenas o por tempora$\mathrm{da}$, los piratas circulan libremente por el territorio como si anduviesen en su propio país, sin ningún tipo de confrontación por parte del Estado colonial español. A través de esta descripción, Dampier no solo configura el paisaje como un algo roto o deshilachado, sino que éste adquiere dimensiones ajurídicas y salvajes, aunque no significa que carezca de intereses comerciales, ya que lo salvaje representa lo que no tiene ley o aquello en donde las leyes no se aplican.

A lo largo de su segundo viaje, el autor centra las relaciones geográficas que ofrece de la zona, siendo su foco de interés qué tan productiva es cada área en cuanto a palo de tinte, en especial las zonas costeras; en qué tipos de embarcaciones son las que pueden navegar por estas zonas, así como cuál es la población actual de los territorios; quiénes los han habitado o si estos han sido atacados por piratas en un pasado, próximo o remoto. Como ya hemos visto, una pieza clave del interés británico en tierras yucatecas es el palo de tinte, motivo central del viaje de nuestro bucanero reformado. Por tanto, Dampier no duda en describir detalladamente las características de la madera, así como sus usos comunes:

"Aquí crecen diversas clases de árboles, no de gran volumen ni altura. Entre ellos, los árboles de palo de tinte prosperan mejor y son muy abundantes, al ser éste suelo apropiados para ellos, ya que no crecen en

45 William Dampier, Dos viajes a Campeche, 61. 
suelo seco, ni se les verá en lodo negro muy copioso. Son en gran medida como nuestros endrinos blancos en Inglaterra, pero generalmente mucho más grandes. La corteza de las ramas jóvenes es blanca y suave, con algunos pinchos creciendo aquí y allá, de modo que un inglés que no conociera la diferencia los tomará por endrinos blancos, pero el tronco y las ramas viejas son negruzcos, la corteza más áspera; con pocos o ningún pincho. Las hojas son pequeñas y tienen la forma de la hoja del endrino blanco común, de verde pálido. Siempre elegimos cortar los árboles viejos de corteza negra, ya que estos tienen menos savia y requieren de poco esfuerzo para astillarlos o cortarlos. La savia es blanca y el corazón rojo. El corazón rojo se utiliza mucho para teñir; por lo tanto, astillamos toda la savia [sic] blanca hasta llegar al corazón y luego queda listo para trasportarse a Europa. Después de que ha sido astillado un poco, se vuelve negro, y si se coloca en agua, la tiñe como tinta, y a veces se ha utilizado para escribir con ella. Algunos árboles tienen cinco o seis pies de circunferencia y estos difícilmente se pueden cortar en troncos lo suficientemente pequeños para que los cargue un hombre sin gran esfuerzo; por ello nos hemos visto forzados a estallarlos. Es una clase de madera muy pesada y se quema muy bien; hace un fuego muy fuerte y claro, que dura mucho. Siempre endurecemos el acero de nuestras armas de fuego, cuando están defectuosas, en un fuego de palo de tinte, si lo podemos conseguir, pero de otro modo, como antes dije, de burton-wood o de vid. El verdadero palo de tinte, pienso yo, crece solo en la región de Yucatán, e incluso ahí solo en algunos lugares cerca del mar. Los principales lugares para ello son, o bien éste, o bien Cabo Catoche, y en el lado sur de Yucatán, la bahía de Honduras"46.

La unicidad de los tintales yucatecos y hondureños hacen de estos territorios un botín preciado para la máquina de producción empresarial inglesa que, para los siglos XVII y XVIII, se había visto fuertemente beneficiada de la primera revolución industrial a través del repunte de la producción textil. Por tanto, aunado al espíritu aventurero del autor, no es de extrañar que Dampier dedique varias páginas a la descripción puntual de los tintales, centrándose en su localización geográfica, su mejor modo de extracción, la calidad y los tipos de tintas que se ob-

46 William Dampier, Dos viajes a Campeche, 145. 
tienen de ellos, así como la posibilidad de diversificar la industria de extracción maderera. En un afán de traducir el paisaje desconocido en un algo reconocible, Dampier compara el palo de tinte con el endrino blanco inglés, pero explica que solo aquel que conozca bien el árbol podría diferenciarlos, al fin y al cabo, la explotación de los tintales es una actividad que requiere experiencia y formación, y para ello estaban los Longwoods-Cutters, un tipo muy particular de leñador que se ha forjado en las huestes del bucanerismo y que difiere sustancialmente del pirata común y del pirata literato.

\section{ConClusión}

En conclusión, si bien el siglo XVI fue el siglo de los descubrimientos inesperados, los repartos, la violencia y la codicia, los siglos XVII y XVIII fueron los tiempos del esplendor etnográfico y la búsqueda sistemática de la definición del método científico propio del empirismo. Este período se caracterizó por la pluma de grandes exploradores aventureros como Dampier que, dada su inclinación natural hacia el mar y el hecho de haberse reformado del bucanerismo a través del ejercicio de una vocación humanista propia del pirata literato, encontraron en la descripción de mundos lejanos un modo de volver a dar sentido al Nuevo Mundo, a través de una serie de acciones cognitivas que lo ordenaban, catalogaban y describían bajo el rigor del common sense inglés, pero con una nueva óptica que abrevaba en gran medida de los postulados de Locke y Bacon. De este modo, en la descripción de Dampier, la costa que enmarca la península de Yucatán es una antinomia que resalta lo roto, deshilachado y fugitivo del territorio, así como de la gente que lo habita, la cual resulta inasible al desaparecer envuelta en tonos fantasmales, que se contrapone con la conformación de un catálogo de recursos naturales que buscaba beneficiar la extracción sistemática de materias primas. Por su parte, como antítesis de lo maya no dominado y fugitivo que habita la costa yucateca, la costa hondureña fue mostrada como territorio amigable y doméstico, aunque con carencia de infraestructura desarrollada, en la que no se detalla ni complejiza la relación con los indios mískitos. 


\section{Bibliografía}

\section{Fuentes primarias y secundarias}

\section{Achivos}

National Portrait Gallery (NPG), Londres, Colecciones, personas, William Dampier.

\section{Publicaciones períodicas}

C. Paredes, Rogelio. "Los viajes de William Dampier (1678-1701) y su recepción europea a través de los libros del Museo Etnográfico de Buenos Aires". Espacios de Crítica y Producción N. 40 (mayo, 2009): 129-135.

Hiernaux, Daniel y Alicia Lindón. "El concepto de espacio y el análisis regional”, Revista Secuencia, N. 25, (enero-abril, 1993): 89-110.

Tun Dzul, Fernando, Jorge Carlos Trejo Torres y Rafael Durán García, "Petenes", CICY, 1, (1996).

Victoria Ojeda, Jorge. "Piratería y estrategia defensiva en Yucatán durante el siglo XVIII”. Revista Complutense de Historia de América, N. 20. (1994): 129-14.

Vidal Ortega, Anrtonino y Raúl Román Romero. "De vasallos británicos a súbditos españoles. Los márgenes borrosos del imperio en el caribe occidental a finales del siglo XVIII y principios del siglo XIX”, Temas americanistas, N. 40 (junio, 2018): 161-187.

\section{Libros}

Curiel Rivera, Adrián. "Viajes del Pirata Dampier a Campeche". En Viajeros por el mundo maya, editado por Carolina Depetris. Mérida: UNAM, 2015, 9-19.

Dampier, William. A New Voyage Round the World. Chapter 1. An account of the Author's return out of the South Seas, to bis landing near Cape St. Lawrence, in the Isthmus of Darien: with occasional description of the moskito Indians, (1681), https:// ebooks.adelaide.edu.au/d/dampier/william/new-voyage-roundthe-world/complete.html\#chapter1 (20 de mayo de 2016).

Dampier, William. "A Map of the Middle Part of America", A New Voyage Round the World. (London: Knapton, 1697), http:/ gu- 
tenberg.net.au/ebooks05/0500461h.html\#0500461h-06 (20 de mayo de 2016)

Dampier, William. Dos viajes a Campeche, con el facsímilar de la edición inglesa de 1705. México: Miguel Ángel Porrúa Editores, 2004. Exquemelin, Alexander O. Piratas en América. Sevilla: Editorial Renacimiento, 2013.

Gerhard, Sandner. Centroamérica \& el Caribe Occidental. Colombia: Universidad Nacional de Colombia, Sede San Andrés, 2003.

Jármy Chapa, Martha de. Un eslabón perdido en la historia. Piratería en el Caribe, siglos XVI-XVII. México: UNAM, 1983.

Lucena Salmoral, Manuel. Piratas, corsarios, bucaneros y filibusteros. Madrid: Editorial Síntesis, 2005.

Macías Zapata, Gabriel. El vacío imaginario. Geopolítica de la ocupación territorial en el Caribe oriental mexicano, México: CIESAS, 2004.

Preston, Diana y Michael. A pirate of Exquisite Mind. Explorer, Naturalist, and Buccaneer: The Life of William Dampier. New York: Walker \& Company, 2004.

Talbot, Ann. The Great Ocean of Knowledge. The Influece of Travel Literature on The Work of John Locke. Leiden-Boston: Brill, 2010. Tomé Martín, Pedro. "La invención del desierto (y los salvajes chichimecas)". En Dinámica y Transformación de la Región Chichimeca, editado por Andrés Fábregas Puig et al. México: Universidad Autónoma de Coahuila, Universidad Autónoma de Zacatecas, Universidad Estatal de California, Universidad de Guadalajara, El Colegio de San Luis, El Colegio de Jalisco, Universidad Autónoma de Nayarit y Universidad Autónoma de Aguascalientes, 2012, 49-64.

Para citar este artículo: Cervera Molina, Ana Elvira. "El bucanero reformado como creador de geografías: espacio y territorio en la costa peninsular yucateca", Historia Caribe Vol. XV No. 37 (Julio-Diciembre 2020): 23-49 DOI: http:// dx.doi.org/10.15648/hc.37.2020.03 